\title{
Report from Mongolia - How much do we know about the incidence of rare cases in less developed countries: a case series Martin W Dünser*1, Otgon Bataar ${ }^{2}$, Albert H Rusher ${ }^{3}$, Walter R Hasibeder ${ }^{4}$, Ganbat Tsenddorj² for the "Helfen Berührt" Study Team
}

\begin{abstract}
Address: ${ }^{1}$ Department of Anesthesiology and Critical Care Medicine, Innsbruck Medical University, Anichstrasse 35, 6020 Innsbruck, Austria, ${ }^{2}$ Department of Anesthesiology and Critical Care Medicine, Central State University Hospital, Ulaanbaatar, Mongolia, ${ }^{3}$ Department of Surgery, Central State University Hospital, Ulaanbaatar, Mongolia and ${ }^{4}$ Department of Anesthesiology and Critical Care Medicine, Krankenhaus der Barmherzigen Schwestern, 4910 Ried im Innkreis, Austria

Email: Martin W Dünser* - martin.duenser@i-med.ac.at; Otgon Bataar - otgon_b2005@yahoo.com; Albert H Rusher - rusher@pobox.com; Walter R Hasibeder - walter.hasibeder@bhs.at; Ganbat Tsenddorj - ganbat_tulga@yahoo.com; the "Helfen Berührt" Study

Team - ganbat_tulga@yahoo.com

* Corresponding author
\end{abstract}

Published: 25 November 2008

Journal of Medical Case Reports 2008, 2:358

is article is avalable from: http://www.jmedicalcasereports.com/content/2/

(C) 2008 Dünser et al; licensee BioMed Central Ltd.

This is an Open Access article distributed under the terms of the Creative Commons Attribution License (http://creativecommons.org/licenses/by/2.0), which permits unrestricted use, distribution, and reproduction in any medium, provided the original work is properly cited.
Received: 16 April 2008

Accepted: 25 November 2008

\begin{abstract}
Introduction: Case reports are important instruments to describe rare disease conditions and give a rough estimation of their global incidence. Even though collected in international databases, most case reports are published by clinicians from industrialized nations and little is known about the incidence of rare cases in less developed countries, which are home to $75 \%$ of the world's population.
\end{abstract}

Case presentation: We present seven patients who suffered from diseases which are either considered to be rare or have not yet been described before according to international databases, but occurred during a 5-month period in one intensive care unit of a less developed country. During the observation period, patients with a spontaneous infratentorial subdural hematoma (Asian, female, $4 \mathrm{I}$ years), general exanthema and acute renal failure after diesel ingestion (Asian, male, 30 years), transient cortical blindness complicating hepatic encephalopathy (Asian, female, 49 years), Fournier gangrene complicating acute necrotizing pancreatitis (Asian, male, 37 years), acute renal failure due to acetic acid intoxication (Asian, male, 42 years), haemolytic uremic syndrome following septic abortion (Asian, female, 45 years), and a metal needle as an unusual cause of chest pain (Asian, male, 4l years) were treated. According to the current literature, all seven disease conditions are considered either rare or have so far not yet been reported.

Conclusion: The global incidence of rare cases may be underestimated by contemporary international databases. Diseases which are currently considered to be rare in industrialized nations may occur at a higher frequency in less developed countries. Reasons may not only be a geographically different burden of certain diseases, limited diagnostic and therapeutic facilities, but also a relevant publication bias. 


\section{Introduction}

Case reports are important instruments to describe rare diseases and give a rough estimation of their global incidence [1]. Although collected in international databases, most case reports are published by clinicians from industrialized nations. Little is known about the incidence of rare cases in developing countries which are home to $75 \%$ of the world's population [2]. In this case presentation, we describe seven patients suffering from diseases which are either considered to be rare or have not yet been described before but occurred during a 5-month period in one intensive care unit (ICU) in a less developed country.

\section{Case presentation}

The eight-bed ICU is located in one of 12 university hospitals in the Mongolian capital of Ulaanbaatar and receives critically ill adult patients with surgical, medical and neurological pathologies. From 1 July until 13 November 2007, a total of 203 patients were treated.

An overview is presented of the clinical course of seven ICU patients with rare or so far unknown disease conditions each followed by a concise review of the current literature. Table 1 summarizes the demographic and clinical data of all the patients. Written informed consent to anonymously present their histories in this case series was obtained from all the patients or their next of kin.

\section{Patient I - Spontaneous infratentorial subdural hematoma}

A 41-year-old Asian woman presented to the emergency department with acute severe headache starting after a 2- day history of diarrhea. Cranial computed tomography revealed an acute left-sided infratentorial subdural hematoma. A cerebral angiogram did not show any abnormalities. The patient denied recent trauma, intake of coagulation active drugs or herbs, or a known bleeding tendency. Plasma (prothrombin time, $10 \mathrm{~s}$; activated partial thromboplastin time, $28 \mathrm{~s}$ ) and cellular (platelet count, 165,000/microliter) coagulation parameters were normal. The patient was fully conscious but complained of nausea and vertigo. She was transferred to the ICU for neurologic monitoring and supportive therapy. Because of the non-compressive size of the hematoma, neurosurgical decompression was withheld. The patient was discharged from the ICU with significantly improved symptoms 3 days later.

Spontaneous subdural hematomas of the posterior fossa are very rare in adults without a history of trauma. Less than 20 cases have been reported in the literature [3]. Almost all were associated either with anticoagulation therapy or coagulatory defects.

\section{Patient 2 - General exanthema and acute renal failure due to diesel ingestion}

During binge drinking, a 30-year-old Asian man with a known allergy to diesel (local skin reactions) ingested an unknown amount of diesel ('several sips') when siphoning fuel from a canister. Within hours he developed fever, chills, coughing and general exanthema (Figure 1A and 1B). On day two, hematuria developed and progressed into oliguria. After 7 days of cefazolin therapy because of pneumonia (Figure 1C) in a county hospital, the patient

Table I: Characteristics of Patients

\begin{tabular}{|c|c|c|c|c|c|c|c|c|}
\hline Patient & $\begin{array}{l}\text { ICU Admission } \\
\text { Diagnosis }\end{array}$ & Gender & Age & Chronic Disease & SAPS II[I6] & TISS 28[I7] & ICU LOS (days) & ICU Outcome \\
\hline 1 & $\begin{array}{l}\text { Acute Infratentorial } \\
\text { SDH }\end{array}$ & $\mathrm{F}$ & 41 & none & 10 & 13 & 3 & survived \\
\hline 2 & Intoxication with diesel & $M$ & 30 & allergy to diesel & 26 & 18 & 8 & survived \\
\hline 3 & Hepatic encephalopathy & $\mathrm{F}$ & 49 & liver cirrhosis & 32 & 15 & 5 & survived \\
\hline 4 & $\begin{array}{l}\text { Acute necrotizing } \\
\text { pancreatitis }\end{array}$ & $M$ & 37 & $\begin{array}{l}\text { chronic pancreatitis, } \\
\text { alcohol abuse }\end{array}$ & 49 & 28 & 10 & survived \\
\hline 5 & $\begin{array}{l}\text { Intoxication with Acetic } \\
\text { Acid }\end{array}$ & $M$ & 42 & alcohol abuse & 56 & 30 & 1 & died \\
\hline 6 & $\begin{array}{l}\text { HUS after Septic } \\
\text { Abortion }\end{array}$ & $\mathrm{F}$ & 45 & alcohol abuse & 38 & 20 & 7 & survived \\
\hline 7 & Foreign Body Extraction & $M$ & 40 & none & 7 & 18 & 3 & survived \\
\hline
\end{tabular}

ICU, intensive care unit; SAPS, simplified acute physiology score; TISS, therapeutic intervention severity score; LOS, length of stay; SDH, subdural hematoma; HUS, hemolytic uremic syndrome. 
was admitted to the ICU with acute renal failure (creatinine, $740 \mu \mathrm{mol} /$ liter). Except for mild respiratory insufficiency and metabolic acidosis ( $\mathrm{pH}$ 7.29; standard bicarbonate, $13.5 \mathrm{mmol} /$ liter; base deficit, $-12 \mathrm{mmol} /$ liter), he was stable. No history of cardiovascular instability could be evaluated. Liberal fluid resuscitation induced polyuria, decreased creatinine levels and evaded hemodialysis. Prednisolone was started at $80 \mathrm{mg}$ and slowly tapered off after the general exanthema had improved.

Whereas localized dermatitis is known after diesel contact [4], no generalized exanthema following diesel ingestion has been reported. An allergic reaction seems to be the most probable cause in our patient. Acute renal failure has so far been observed in at least three patients after skin contact or diesel aspiration. Aliphatic hydrocarboninduced hemolysis with hemoglobinuria, direct tubular toxicity, and allergic nephritis are possible pathogenetic mechanisms.

\section{Patient 3 - Transient cortical blindness complicating hepatic encephalopathy}

A 49-year-old Asian woman with liver cirrhosis due to unspecified viral hepatitis was admitted to the ICU with coma (Glasgow Coma Scale, 9 pts; total bilirubin, 38 $\mu \mathrm{mol} /$ liter; blood sugar, $7 \mathrm{mmol} /$ liter; arterial lactate, 2.5 $\mathrm{mmol} /$ liter; plasma albumin, $35 \mathrm{mg} / \mathrm{dl}$ ). Loss of consciousness was preceded by diarrhea followed by gradual visual impairment. Cranial computed tomography, lumbar puncture and microbiological specimen were normal. In the electroencephalogram, triphasic waves and a delta rhythm were found. Two days after initiation of enteral lactulose $(6 \times 30 \mathrm{ml} /$ day $)$ and supportive treatment, the patient's conscious state improved. Ophthalmologic examinations at ICU admission and after the patient had

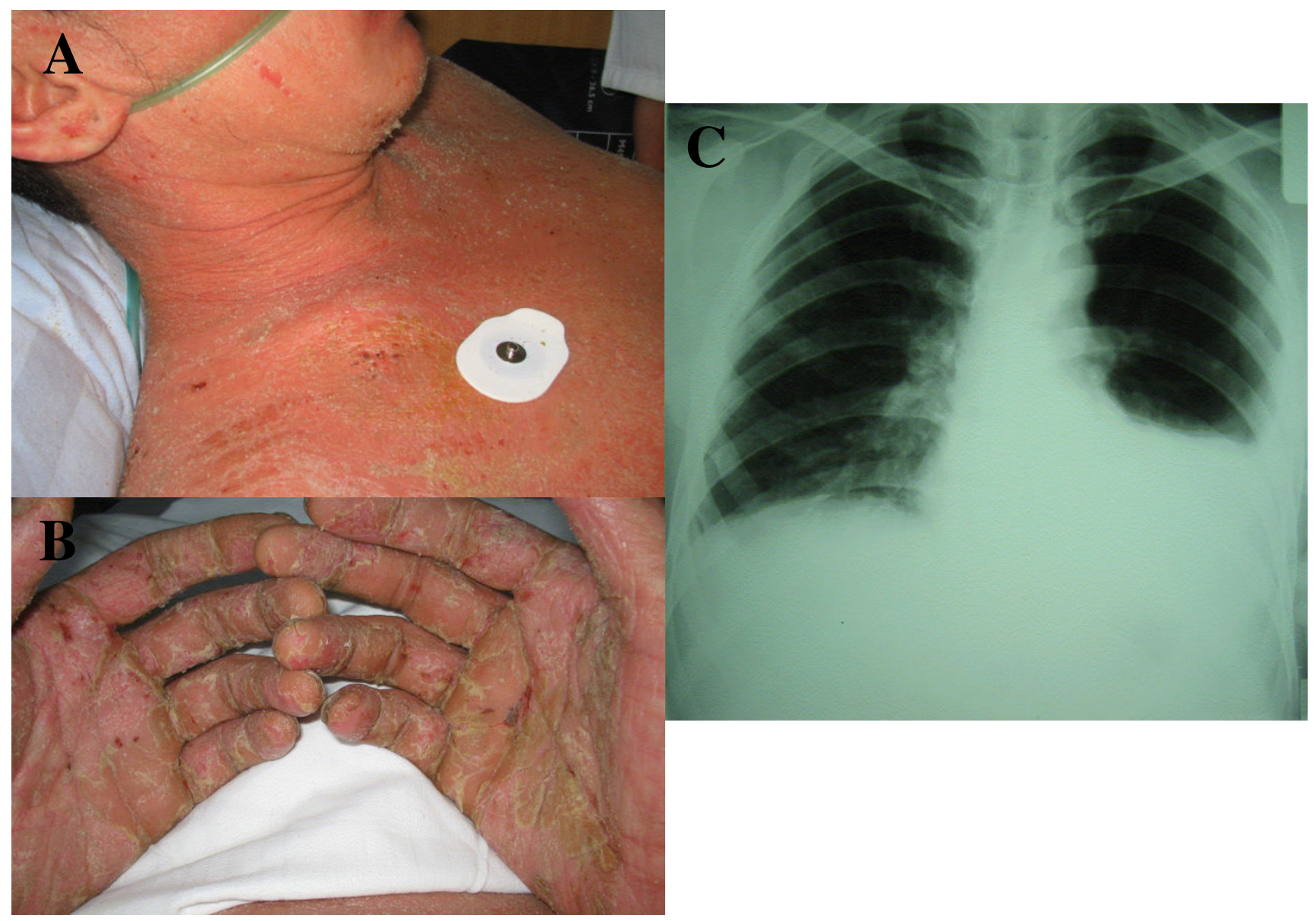

Figure I

General exanthema (A, B) and left lower lobe pneumonia $(C)$ after diesel ingestion. 
regained full consciousness revealed no ocular pathology. One week later, the patient was discharged from the ICU with improved but still impaired vision.

Cortical blindness associated with hepatic encephalopathy was first described in 1979. Since then, only four case reports have been published. As in our case, visual disturbances preceded the loss of consciousness in all reports. The pathogenesis of hepatic blindness is unknown but may include hypotensive episodes and impaired blood brain-barrier function leading to cortical and subcortical edema [5].

\section{Patient 4 - Fournier gangrene complicating acute necrotizing pancreatitis}

After binge drinking, a 37-year-old Asian man was admitted to the ICU with severe acute pancreatitis and multiple organ dysfunction (acute delirium; acute lung injury; total bilirubin $101 \mu \mathrm{mol} /$ liter; creatinine $238 \mu \mathrm{mol} /$ liter). His general condition improved with symptomatic ICU treatment. After a 10-day course of antibiotic prophylaxis $(4 \times$ $1 \mathrm{~g}$ cefotaxime/day), pancreas necroses remained sterile (fine needle puncture). After ICU discharge, the patient developed extensive necroses of the scrotum and perineum (Fournier gangrene) requiring repeated surgical necrosectomy.

So far, scrotal involvement has been reported as a complication of acute necrotizing pancreatitis in four patients [6]. According to the current literature, necrosis culminating in Fournier gangrene is a yet unknown complication of pancreatitis. Comparable to the patients experiencing necrosis of the scrotum, descending retroperitoneal necroses most likely resulted in Fournier gangrene in our patient.

\section{Patient 5 - Acute renal failure due to acetic acid intoxication}

During binge drinking, a 42-year-old Asian man, a chronic alcoholic, involuntarily ingested $~ 100 \mathrm{ml}$ of $80 \%$ acetic acid. After hospital admission, he developed intravascular hemolysis (hemoglobin, $57 \mathrm{~g} /$ liter; lactate dehydrogenase, 3752 IU/liter) and acute renal failure (creatinine, $1700 \mu \mathrm{mol} /$ liter). When transferring the patient from the nephrological department to the ICU, he massively aspirated and died due to refractory pulmonary failure soon after ICU admission.

According to the experience of Mongolian physicians, acetic acid ingestion is a frequent intoxication requiring hospital admission. At least three cases of acetic acidassociated acute renal failure are observed in this hospital each year. In contrast, the current literature reports acute renal dysfunction to be a rare complication of acetic acid intoxication. So far, six case reports/series have been pub- lished. As in this patient, hemolysis with hemoglubinuria caused kidney injury in most patients [7], but direct toxic effects of acetic acid on renal tubules may also be involved [8].

\section{Patient 6 - Hemolytic uremic syndrome following septic abortion}

A 45-year-old Asian woman suffered from septic abortion during gestational week 23 . After curettage and initiation of antibiotic therapy $(4 \times 1 \mathrm{~g}$ ampicillin/day because of $E$. coli growing from an intrauterine swab), the patient was stable and free of organ dysfunctions. On postoperative day two, jaundice and oliguria developed, and she was transferred to the ICU. Despite fluid resuscitation, anuric renal failure (creatinine, $470 \mu \mathrm{mol} /$ liter) developed. Repeated transfusions of red blood cells were required because of hemolytic anemia (hemoglobin, $61 \mathrm{~g} /$ liter; lactatedeyhdrogenase, 3027 IU/liter). Blood analysis revealed fragmentocytes and thrombopenia (platelets, 48,000 /microliter). Intermittent hemodialysis was started. One week after ICU admission, the patient was discharged with rising erythrocyte and platelet counts. Because of persistent anuria, hemodialysis was continued for another 2 weeks. Subsequently, renal function gradually returned to normal.

Although extraintestinal causes of hemolytic uremic syndrome are known [9], only one case following septic abortion has been published [10]. Comparable to intestinal hemolytic uremic syndrome, the E. coli isolated from the uterine cavity in our patient not only caused abortion but most probably also hemolysis and acute renal failure. Although further laboratory specification of the pathogen was not possible, it is likely that the clinical condition was caused by Shiga toxin [9].

\section{Patient 7 - A metal needle as an unusual cause of chest pain}

A 41-year-old Asian man presented to the emergency department with subacute recurrent chest pain. The electrocardiogram and biochemical laboratory parameters were normal. Chest fluoroscopy revealed a metal needle in the mediastinum. The patient could not remember having swallowed the needle. Since no part of the needle could be reached through endoscopy, the patient was scheduled for surgery. Choosing a left lateral thoracotomy, the needle could only partly be removed because scar tissue most probably had grown through the eye of the needle and prevented it from being extracted without causing damage to the ventricular wall (Figure 2). Adhesions between the posterior pericardium and the esophagus suggested that the needle had penetrated into the heart from the esophagus. The immediate postoperative course was complicated by respiratory problems but was 


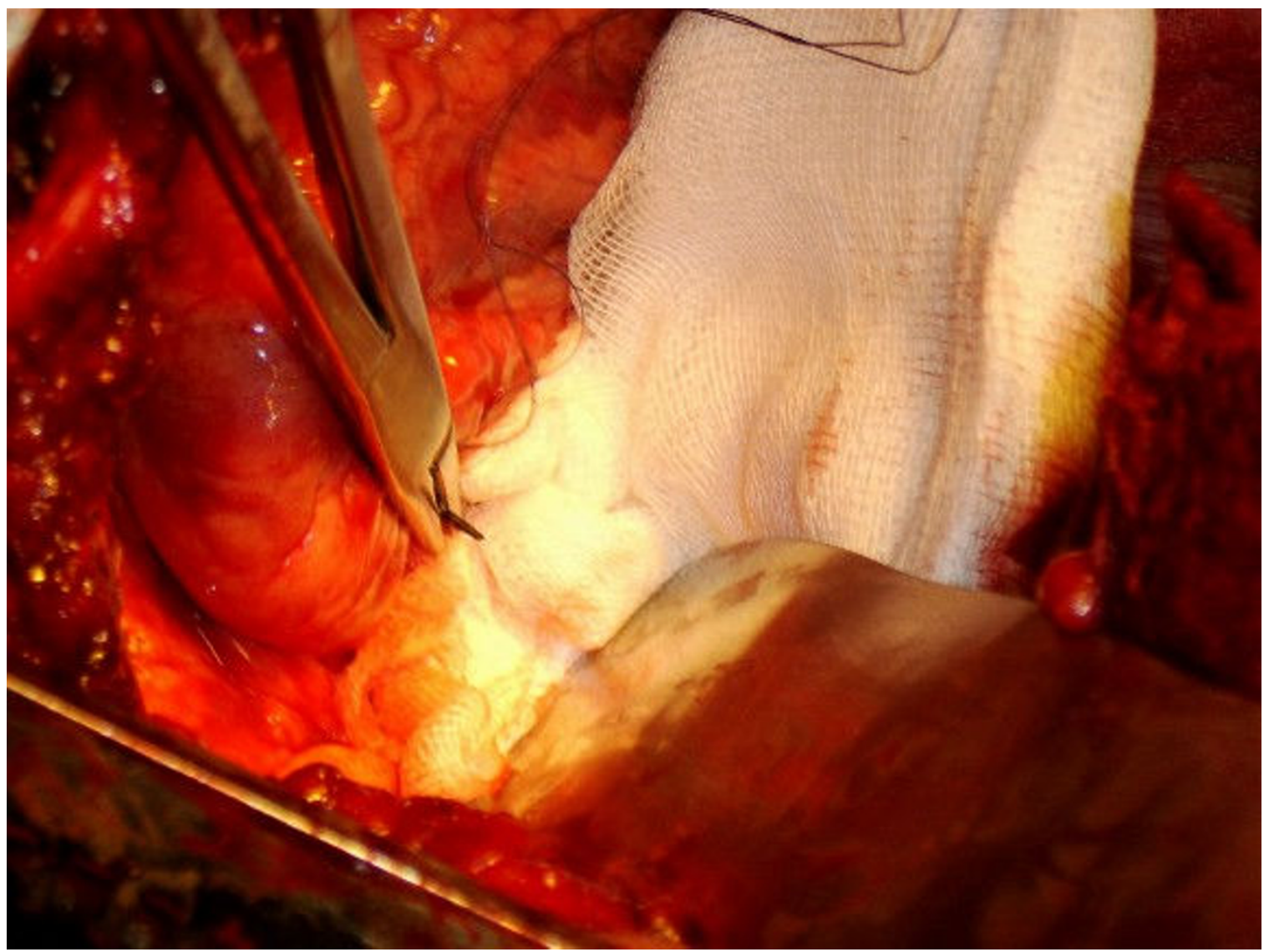

Figure 2

Intraoperative situs during the procedure to extract a metal needle lodged in the ventricular wall and causing subacute chest pain.

uneventful afterwards. Three months after surgery, the patient still complained of intermittent mild chest pain.

Even though more than 100 cases of aortoesophageal fistulas have been reported, only a few cases of foreign body penetration into the heart are known [11].

\section{Discussion}

According to the literature all disease conditions presented are either considered rare (Patients 1, 3, 5, 6, 7) or have not yet been reported (Patients 2,4). Although no condition was observed more than once, the occurrence of seven such cases during a comparatively short time suggests an unusual accumulation, at least in the ICU evaluated. It is definitely possible that this is an unusual occurrence but it may also indicate that rare cases occur more frequently in less developed countries. This brings up the question whether the global incidence of certain disease conditions is underestimated by the current literature which is largely based on reports from highly developed countries. It is at least worthwhile to reflect on why certain diseases assumed to be rare could occur more often in less developed countries.

The higher disease burden in developing countries $[12,13]$ makes the occurrence of unusual cases more likely. Moreover, certain diseases (for example, tropical diseases) are more frequent in the developing world. For example, the high incidence of chronic liver diseases in Mongolia [14] makes it probable that rare complications such as transient blindness associated with hepatic encephalopathy are observed more frequently. The widespread availability of potential toxins (for example, acetic acid) and the lack of adequate protective measures (for example, when handling fuel) result in a higher incidence of intoxications in less developed countries. Rare compli- 
cations are further facilitated by variable diagnostic and therapeutic standards. It may be argued that earlier and more aggressive fluid resuscitation could have prevented acute renal failure in the two patients with acetic acid and diesel ingestion. Similarly, better imaging techniques and the possibility of performing interventional radiological procedures would have allowed earlier detection of the descending necroses and drainage in the pancreatitis patients.

Considering the low number of active scientists in developing countries [15], it is less likely that rare cases occurring in these regions will be published. This may be the reason why international databases suggest acute renal failure to be a rare complication of acetic acid poisoning while Mongolian physicians encounter this condition quite frequently. It may be hypothesized that further diseases remain either unknown or their global incidence underestimated simply because cases from less developed countries do not appear in international databases.

However, these points must not lead to the assumption that medical conditions which appear unclear in developing countries are rare cases that have not been observed in the medical literature. In contrast, it is much more likely that inadequate diagnostic facilities and limited educational standards preclude the diagnosis of well-known diseases. Given the possibility to perform appropriate diagnostic procedures and the clear disease presentation in our patients, it is unlikely that these cases are indeed "overlooked" common disease processes.

\section{Conclusion}

The global incidence of rare cases may be underestimated by contemporary international databases. Diseases which are currently considered to be rare in industrialized nations may occur at a higher frequency in less developed countries. The reasons may not only be a geographically different burden of certain diseases, limited diagnostic and therapeutic facilities but also a relevant publication bias.

\section{Abbreviations \\ ICU: intensive care unit}

\section{Consent}

Written informed consent was obtained from the patients for publication of this case report and any accompanying images. A copy of the written consent is available for review by the Editor-in-Chief of this journal. In the case of patient 5 who died, consent for publication was sought from his next of kin.

\section{Competing interests}

The authors declare that they have no competing interests.

\section{Authors' contributions}

MWD made a substantial contribution to conception and design, interpreted the data and drafted the manuscript. OB gathered the data, interpreted the data and helped in drafting the manuscript. AHR gathered the data and helped in drafting the manuscript. WRH interpreted the data and helped in drafting the manuscript. GT made a substantial contribution to conception and design, interpreted the data and helped in drafting the manuscript. All authors read and approved the final manuscript.

\section{Acknowledgements}

No funding related to the study itself. All funding related to medical support of the presented intensive care unit was based on donations from the medical aid organization "Helfen Berührt".

\section{References}

I. Vandenbroucke JP: Case reports in an evidence-based world. J $R$ Soc Med 1999, 92:159-163.

2. The Human Development Report 2007/2008 [http:// hdr.undp.org]

3. Berhouma M, Houissa S, Jemel H, Khaldi M: Spontaneous chronic subdural hematoma of the posterior fossa. J Neuroradiol 2007, 34:2I3-2I5

4. Wahlberg JE: 'Green diesel' - skin irritant properties of diesel oils compared to common solvents. Contact Dermatitis 1995, 33:359-360

5. van Pesch V, Hernalsteen D, van Rijckevorsel K, Duprez T, Boschi A, Ivanoiu A, Sindic CJ: Clinical, electrophysiological and brain imaging features during recurrent ictal cortical blindness associated with chronic liver failure. Acta Neurol Belg 2006, 106:215-218.

6. Lin YL, Lin MT, Huang GT, Chang YL, Chang H, Wang SM, How SW: Acute pancreatitis masquerading as testicular torsion. $\mathrm{Am} J$ Emerg Med 1996, 14:654-655.

7. Sangüesa Molina JR, Macía Heras ML: Acute oliguric kidney failure secondary to acetic acid poisoning. An Med Interna 1999, 16(9):46|-462.

8. Boseniuk S, Rieger C: Acute oral acetic acid poisoning - case report. Anaesthesiol Reanim 1994, 19(3):80-82.

9. Blackall DP, Marques MB: Hemolytic uremic syndrome revisited: Shiga toxin, factor $\mathbf{H}$, and fibrin generation. Am J Clin Pathol 2004, I 2 I:S8I-S88.

10. Sens YA, Miorin LA, Silva HG, Malheiros DM, Filho DM, Jabur P: Acute renal failure due to hemolytic uremic syndrome in adult patients. Ren Fail 1997, 19:279-282.

II. Medina HM, Garcia MJ, Velazquez O, Sandoval N: A 73-year old man with chest pain 4 days after a fish dinner. Chest 2004, 1 26:294-297.

12. Mathers CD, Loncar D: Projections of global mortality and burden of disease from 2002 to 2030. PLoS Med 2006, 3:442.

13. Ezzati M, Lopez AD, Rodgers A, Hoorn S Vander, Murray CJ, Comparative Risk Assessment Collaborating Group: Selected major risk factors and global and regional burden of disease. Lancet 2002, 360:1347-1360.

14. Oyunsuren T, Kurbanov F, Tanaka Y, Elkady A, Sanduijav R, Khajidsuren $O$, Dagvadorj B, Mizokami M: High frequency of hepatocellular carcinoma in Mongolia; association with mono-, or coinfection with hepatitis C, B, and delta viruses. I Med Virol 2006, 78: 1688-1695.

15. Langer A, Díaz-Olavarrieta C, Berdichevsky K, Villar J: Why is research from developing countries underrepresented in international health literature, and what can be done about it? Bull World Health Organ 2004, 82:802-803.

16. Le Gall JR, Lemeshow S, Saulnier F: A new Simplified Acute Physiologic Score (SAPS II) based on a European/North American multicenter study. JAMA 1993, 270:2957-2963.

17. Miranda DR, de Rijk A, Schaufeli W: Simplified Therapeutic Intervention Scoring System: the TISS-28 items - results from a multicenter study. Crit Care Med 1996, 24:64-73. 